\title{
Narratives in Rhetorical Discourse
}

Stefan Iversen

Created: 31. January 2014 Revised: 31. January 2014

\section{Definition}

Rhetoric can be defined as "the use of symbols to induce social action" (Hauser 2002: 3), thus making rhetorical discourse texts aimed at specific audiences for specific reasons in specific situations. While they are rarely complete narratives or completely narrative, such discourses often use narrative elements as means to their argumentative, convincing or otherwise motivational ends. The study of narratives in rhetorical discourse takes as its object discourses that primarily serve argumentative functions in contrast to aesthetic or didactic functions. It overlaps with subfields of narrative study, most importantly rhetorical narratology, research on storytelling (Norlyk, Wolff Lundholt \& Hansen $\rightarrow$ Corporate Storytelling [1]) and Narrative Inquiry (Bamberg $\rightarrow$ Identity and Narration [2]). In contrast to more formal approaches to narrative such as classical narratology (Meister $\rightarrow$ Narratology [3]), these approaches share an interest in the ways in which narratives move or influence readers and audiences. They all understand narrative as situated in a communicative framework.

\section{Explication}

Being a form of rhetorical criticism, the study of narratives in rhetorical discourse offers analytical and evaluative readings of narratives and narrative elements in situated discourse or acts aimed at persuading, convincing, uniting or otherwise moving people towards specific ends. It differs from narrative inquiry (as practiced in psychology, ethnography, socio-linguistics and the social sciences) in that the primary object of narrative inquiry is personal/group identity or linguistic competence. It also differs from rhetorical narratology as practiced in literary criticism in that the latter conceives "of narrative as an art of communication" (Phelan 2005a), while the study of narratives in rhetorical discourse works primarily with narratives in rhetorical communication. Thirdly, in methodology as well as in expected output, it differs from theories of storytelling (e.g., corporate communication, branding), when storytelling is understood as the strategic use of narratives: where the study of storytelling draws heavily on quantitative methods in 
attempts to maximize specific communicative effects, rhetorical criticism combines close reading with contextual analysis in order to arrive at normative judgments.

Despite different takes on what delimits rhetorical discourse, most researchers engaged with the study of narratives in rhetorical discourse would agree on a core corpus including, at the very least, all types of political communication, public debate, critical journalism and most types of public address bearing on contested issues. Among the relevant genres, found across media and communication platforms, are speeches, presentation material, public dialogue, rallies, blogs, manifestos, constitutions and legislation, declarations, letters of opinion, editorials and demonstrations. An example would be Barack Obama's 2009 address to a joint Session of Congress on health care. Here, Obama combined the retelling of Ted Kennedy's experience of children suffering from cancer with a larger narrative of what constitutes the American character in order to persuade his audience to act in favor of the proposed reform. Another example of a rhetorical discourse employing narratives would be Invisible Children's Kony 2012 campaign (www.kony2012.com [4] ). This campaign used videos distributed online to raise awareness and inspire the public to take action toward catching an African war criminal. The controversy surrounding the campaign was partly due to the intense use these videos made of narrative elements, infusing stories of the victims and the story of the perpetrator not only with the story of the rhetor of the multimodal production but also with a story about the inscribed audience.

The foundational debates in this subfield of narrative study are concerned with delimiting a) the question of what constitutes rhetorical discourse and b) the question of what constitutes a narrative or a narrative element in rhetorical discourse.

a) The question of what makes a discourse rhetorical has a long history and is still being debated, with positions spanning a continuum from very narrow definitions (reserving the term for, say, explicitly persuasive public verbal genres) to very inclusive ones (having it cover all kinds and aspects of human symbol use). In modern rhetorical criticism-often referred to as "the new rhetoric," a term borrowed from Olbrechts-Tyteca and Perelman's and seminal Traité de I'argumentation: La nouvelle rhétorique (1958), and from Kenneth Burke's writings from the 1950s-two approaches stand out in the attempt to anchor the term "rhetorical discourse." The first ties the notion of rhetoric to the concept of rhetorical situation. Bitzer (1968) defined rhetorical discourse as a specific response to a specific situation: "it is the situation which calls the [rhetorical] discourse into existence" (5) For him, a rhetorical situation comprises three necessary and sufficient components: an exigence ("an imperfection marked by urgency," a 
problem modifiable by discourse), a rhetorical audience (those "capable of being influenced by discourse and of being mediators of change") and constraints (persons or events with the "power to constrain decision and action needed to modify the exigence") (6-7). While often both highly artistic and formally elaborate, rhetorical discourse is thus a means to an end, and that end exists as a more or less explicit and changeable occurrence or state of affairs in the real world. Bitzer's insistence on this one-way causality between occurrence and rhetorical discourse (his example is the assassination of Kennedy) has since been challenged (Vatz 1973, 2009) and modified (Hauser 2002; Kjeldsen 2008). However, the idea of distinguishing rhetorical discourse from, say, poetic or scientific discourse with recourse to the degree of manifest intentionality and function remains a crucial and distinctive move for this approach to rhetorical criticism.

The second way of delimiting the term "rhetorical discourse" takes its cue from Burke's notion of rhetoric as identification. A major thrust in Burke's work is the intention to expand the idea of what counts as rhetoric from the neo-Aristotelian notions of rhetorical discourse as finding the most persuasive elements in a given situation to a much broader concept of rhetoric as any more or less conscious process of identification through the use of symbols: "The difference between the 'old' rhetoric and the 'new' rhetoric may be summed up in this manner: whereas the key term for the 'old' rhetoric was persuasion and its stress was upon deliberate design, the key term for the 'new' rhetoric is identification and this may include partially 'unconscious' factors in its appeal” (Burke 1951: 203). According to Burke, most actions are motivated by processes beyond rational persuasion, processes of identifying with, say, an idea, a world view, an image or a tonality. These forms of identification are constructed through what Burke calls consubstantiality (positive identification: "I am like this") and diversification (negative identification: "I am different from that").

b) Being focused on rhetorical discourse with narrative elements rather than on fullfledged narratives, the different positions in the study of narratives in rhetoric result in rather different definitions of what a narrative is and on what epistemological and ontological level it might function. In a recent introduction to the field, Rowland (2009) suggests differentiating between two main functions of narratives in rhetorical texts: epistemic and persuasive. The epistemic function has to do with the ability of narrative to function as a tool for "understand[ing] the world" (121). Through the sequential, teleological structure of narrative, we ascribe meaning and value to past and future occurrences and establish relationships between them. According to Rowland, the persuasive function is an umbrella term that brings together different but often connected ways in which narratives produce persuasive effects in a given rhetorical situation: narratives "keep the attention" of 
the audience, they "create a sense of identification" between the sender/subject matter and the audience, they help "break down barriers" (122) through their ability to show a different world view from the inside, tapping into emotions and values by zooming in on particular people undergoing particular changes. While Rowland's distinction between epistemic and persuasive is helpful for a quick overview of the positions in the field, it runs the risk of highlighting similarities where differences might matter more. Visualized along a spectrum, these differences range from, at the one end, conceiving of narrative as an optional stylistic device, to, at the other end, conceiving of narrative or narrative understanding as a fundamental, epistemological prerequisite for communication to take place at all.

\section{History of the Term}

Although the systematic study of narratives on rhetorical discourse is a fairly recent enterprise in the sense it is being discussed here, the question of the role of narratives in rhetorical discourse, as well as the question of the power of fictional narratives to move audiences, was raised already in classical thinking, most notably by Aristotle and Quintilian. A major surge of interest took place during the 1980s, inspired by a more general turn toward narratives in history (White), psychology (Bruner) and philosophy (Ricœur; Maclntyre). Fisher and his idea of the narrative paradigm stands as perhaps the most radical contribution to this upsurge, partly due to its own ideas and partly due to the debate and discussion it provoked. Lucaites and Condit disagreed with some of the basic assumptions of Fisher's reasoning and suggested instead a rethinking of insights from classical rhetoric. Apart from some additions to and revisions of Fisher's basic categories, the study of narratives in rhetorical discourse has lain rather dormant in recent years. This is surprising, given the degree to which narratives and elements of narratives thrive in present-day political discourse.

\subsection{Statements of Facts: Classical Rhetoric}

With Rhetoric and Poetics, Aristotle established an early and influential division between two kinds of aesthetic consideration. In this division, fully invented narratives belong to poetics. To Aristotle, narratives play minor roles in the nonfictive rhetorical genres of the forensic, the deliberative and the epideictic in that they are confined to the following two functions: examples and statements of facts ( narratio). Narratives as examples are a type of proof, pertinent in deliberative speeches and divisible into two types: "one consisting in the mention of actual facts, the other in the invention of facts by the speaker" (Aristotle 1984: 1393). Narratives as statements of facts come under forensic speeches, where in a sequential manner they represent the events of the (juridical) case to the audience (jury). For Aristotle, 
then, narratives in rhetorical discourse are tools for representation, either in order to make the nature of previous events temporarily present or to use former or invented events as images for things that could or should happen.

Quintilian elaborates on the notion of narratives in rhetorical discourse as narratio, which he defines as "the persuasive exposition of that which either has been done, or is supposed to have been done" (1920: 67). Crucial to this exposition is that it avoids the temptation to dwell on artificiality, ornamentation and other forms of poetry: the narratio should remain as factual as possible.

Seen from the perspective of classical rhetoric, then, narratives in rhetorical discourse are or ought to be markedly different from invented narratives on a formal as well as on a functional level. Invented or fictional narratives strive towards formal complexity, ambiguity and turning points while narratives used in rhetorical discourse should strive for simplicity, clarity and reliability. Narratives used for rhetorical purpose should fit the situation in which they are employed; they should be persuasive in the Aristotelian sense of that term.

\subsection{The Narrative Paradigm: Fisher}

The premise informing Fisher's concept of the narrative paradigm is that a large part of actual argumentation, including most cases of individual and social decisionmaking, relies on narratives rather than on what is traditionally taken to be argumentative discourse. Taking his cue from MacIntyre (Maclntyre 1981), Fisher conceives of humans as essentially storytelling animals, as homo narrans, choosing what seems like the right path through life with recourse to stories: "the world is a set of stories which must be chosen among to live the good life in a process of continual recreation. In short, good reasons are the stuff of stories" (1984: 8).

According to Fisher, this insight calls for a major reorientation of rhetoric and communication studies. Rather than treating narrative as a specific genre or texttype, it should be seen as a meta-discourse, as a fundamental way of rationalizing behavior thanks to "narrative rationality." Fisher's position stands "in marked contrast to the view that narration is merely an element in rhetorical discourse or is a specific literary genre" (1984: 59). The concept of narrative paradigm thus moves beyond the distinction initially set up in this article between reading narrative as rhetoric and reading narrative elements in rhetorical discourse.

In the narrative paradigm, the sequential orderings of narrative serve different functions: they bind together the disparate experiences of individuals into a coherent identity by connecting the choices and values of the individual to the commonly shared narratives that carry the values of social identities. How, then, do 
we choose which stories and thus which good reasons to identify with and follow?

In order to analyze the relations between different narratives as well as between narratives and those who identify with them, Fisher introduces a distinction between what he calls narrative probability and narrative fidelity. A story worth identifying with must "ring true to the human condition" (Fisher 1987: 176). It accomplishes this by realizing a double coherence: internally, it must cohere as a structure (it must "hang together" and be "free of contradiction" (Fisher 1985: 349). Externally, it must cohere with what is taken to be the case in the culture where the story appears: it must accord "with the logic of good reasons" (349), i.e. display a certain degree of fidelity with regard to existing narratives. The decision to identify with or discard a line of narrative rationality is thus made with recourse to the structure of the proposed story as well as to the ways in which the story connects to other stories already accepted as valid in the life of the group or individual.

Comparing Fisher's idea of the role of narratives to the one in classical rhetoric, the differences are striking. Rather than a statement of the facts or an optional example used in an act of persuasion, narrative becomes epistemologically unavoidable, part of the very ground upon which arguing as well as most other types of communication take place.

Fisher's theory stirred up an intense debate in American rhetoric during the 1980s, the first wave of which came in a special issue of The Journal of Communication in 1986 (vol. 35.4). In the discussions of the narrative paradigm, two weaknesses were pointed out by several rhetoricians. The first regards what appears to be a major limitation inherent in Fisher's concept of fidelity. If narrative reasoning comes about only when a new narrative shares values with what is already taken to be reasonable, how does the paradigm explain actual change in value and belief systems? (Kirkwood 1992: 75; see Stroud 2002 for an expanded version of this critique).

A second, perhaps more fundamental problem, regards the epistemological omnipresence of narratives as stated by Fisher's idea of a paradigm. Rowland (1989 ) uses three case studies to argue convincingly against the description of narrative as a universal meta-discourse. Traditional rhetorical texts without storylines or plot as well as plot-rich fiction with strange entities clearly resist the application of narrative fidelity and probability. Rowland concludes that "the domain in which narrative approaches to rhetoric should be utilized is much narrower than Fisher and others have suggested" (1989: 51).

In a more indirect but also more consequential way, Lucaites and Condit (1985) voiced a similar critique, not only questioning the possibility and validity of a pan- 
narrative approach but also suggesting another way of studying narratives in rhetorical discourse.

\subsection{Narratives as Lenses: Lucaites and Condit}

Lucaites and Condit argue that narratives carry different functions in different types of discourse. Their suggestion is thus diametrically opposed to the metadiscursive ambitions of the narrative paradigm. They distinguish between poetic, dialectic and rhetorical discourse, motivated by, respectively, the search for aesthetic pleasure, enlightenment and power. Drawing on Quintilian, they suggest analyzing narratives in rhetorical discourse on the basis of this type of discourse's need to be adapted to specific contexts, audiences and purposes. These three subfunctions all share the quality of specificity in that rhetorical discourse, as well as the narrative elements appearing in it, is bound to a specific situation.

The contextual sub-function stems from the fact that a rhetorical discourse is involved in an ongoing negotiation between at least two parties. This has two formal consequences. The first is that it requires a narrative within a rhetorical discourse to be unequivocal (it must "invite only one interpretation") in order to clearly state the rhetor's case. Second, because it is part of a discourse that attempts to move actual audiences to action, it must "stop short of the formal stage of plot 'resolution' by virtue of its purpose to encourage audience enactment" (Lucaites \& Condit 1985: 100).

The audience function is linked to the fact that rhetorical discourse is always directed at a specific audience. It also has two formal consequences, requiring that narrative rhetoric be consistent and concise. Consistency becomes important because the use of a narrative should be coherent internally and fit the context in which it occurs, meaning that it should strive to make sense in connection with the reality of the intended audience. The requirement of concision follows from the fact that rhetorical discourse should avoid putting unnecessary strain on the patience of the audience.

The third sub-function-purpose-is the one that most emphatically makes narratives in rhetoric stand apart from, say, fictional narratives. To Lucaites and Condit, narratives in rhetorical discourse are always a true subset of a rhetorical artifact with an often very specific purpose, tied inextricably to the rhetor or sender of the artifact. The first formal consequence of this explicit link between a rhetorical artifact and its sender is that the narrative should aim for a "formal unity of narrator, author, and speaker" (101). The second consequence is that the ethos of the rhetor by necessity is connected to the impact of the narrative elements as well as vice versa. 
As should be evident, Lucaites and Condit express doubts about the validity of Fisher's promotion of narrative to the position of master metaphor for human communication. Instead, their suggestion can be summed up as a poetics of the adequate use of narrative elements in rhetorical situations, an approach compatible with the ideas of narratives as statements of facts or examples: a "rhetorical narrative is a story that serves as an interpretative lens through which the audience is asked to view and understand the verisimilitude of the propositions and proof before it" (94).

It is tempting to posit Fishers' and Lucaites and Condit's positions as extremes in a polarized discussion. Fisher deals with the epistemological qualities of narratives of social and individual identity but lacks adequate tools to analyze the specificity of the rhetorical narrative. Lucaites and Condit analyze these specifics but offer no tools for dealing with matters of more general narrative identification. Or, seen from another perspective: Lucaites and Condit offer few reasons for choosing narratives as part of an attempt to convince while Fisher claims that it is impossible to avoid narratives even if one tried to do so.

\subsection{Recent Developments}

The difference is rather striking if one compares the massive proliferation of narrative studies with the amount of work done on narratives in rhetorical discourse during the last twenty years. As McClure put it in 2009: "in rhetorical theory and criticism narrative and the narrative paradigm have become virtually dead subjects" (2009: 189). Nevertheless, several pieces of interesting research have come out in the 2000s and early 2010s, most of which elaborate on Burke's notion of identification while some also engage with aspects of Fisher's concept of the narrative paradigm.

Any scholar engaging with the narrative paradigm will have to position herself with regards to the double critique of the paradigm: on the one hand, its problem of being too general and wide, effectively turning narrative, as Rowland puts it, into a general "model for understanding the world" (Rowland 1989: 43); on the other hand, the problem of its analytical tools (probability and fidelity) being too narrow and inept at dealing with phenomena like the "inventional possibilities of new narratives, the rhetorical revision of old narratives, and the appeal and acceptance of improbable narrative accounts" (McClure 2009: 191).

Stroud has taken issue with aspects of the second problem in a series of articles (Stroud 2002, 2003, 2004). Challenging Fisher's ideas of probability and fidelity with a case that "involves contradictions at the level of values within a text and the 
reader's necessitated activity of trying to synthesize or reconcile such contradictions," Stroud revises the definitions of fidelity and probability to better account for situations where audiences encounter and make sense of discourse with "contradictory value structures" (2004: 42), which Stroud calls "multivalent narratives."

A more radical repositioning of the narrative paradigm is presented by the Burke expert McClure (2009). In stark contrast to the critique of the expansive ambitions of the narrative paradigm, McClure moves towards an "extension of the [narrative] paradigm that is consistent with poststructuralism" (191) through a further widening of the range of the Burkean notion of identification.

\section{Topics for Further Investigation}

The lack of contemporary research on narratives in rhetorical discourse has left a range of pressing questions unanswered, some stemming from unresolved issues in the existing research, others raised by the transformations of communication brought on by, among other things, processes of digitalization and globalization.

A major challenge in relation to the first set of questions is the problem of the epistemological reach and impact of narrative effects in rhetorical discourse. Are we to understand narratives (as Fisher argued) as a general master trope for human existence? Or are we rather, as Lucaites and Condit argued, to understand them as examples and statements of facts? Connected to this question of the place of narration are questions of the deliberative functions of narratives. To what extent should they be treated as subduing and thus a threat to processes of deliberation (Salmon [2007] 2010) or as subversive and thus a vehicle for such processes? Following this line of thought, what might the study of narratives in rhetorical discourse learn from work done on the ways in which narratives are used as tools for reversing or transforming existing opinions through the use of so-called counternarratives (Bamberg \& Andrews 2004; Godall 2010)?

A promising but so far untapped field of investigation exists between work in rhetorical criticism of narratives and recent work in social sciences and sociology on narratives and storytelling in society and politics. Expanding the focus on personal life stories in narrative inquiry to a wider perspective of what Holstein and Gubrium call "the social life of stories" (2012: 3), several researchers offer new insights on, as the subtitle of Polletta (2006) dubs it: "storytelling in protest and politics."

Seen from the more rigorous viewpoints of classical and postclassical narratology, the study of narratives in rhetorical discourse seems lacking when it comes to definitions and delineations of the objects of study. Does it make sense to establish 
a set of necessary and sufficient conditions for narratives in rhetorical discourse, or are we better off with granular or prototypical descriptions? How much and what parts of narrative elements (or degrees of narrativity; Abbott $\rightarrow$ Narrativity [5]) should be present in order for a rhetorical discourse to warrant a narrative analysis? And what and how does it matter whether a narrative in a rhetorical discourse employs strategies of fictionalization (Walsh 2007; Schaeffer $\rightarrow$ Fictional vs. Factual Narration [6])?

The second set of questions has to do with the fact that the rhetorical narratives of today thrive in a new media ecology, making different demands on as well as offering new options for senders, audiences and the modalities of expression. With the shift from mass media to mass self-communication, and with the displacements of former distinctions between public and private brought on by social media, the forms and functions of narratives in rhetorical discourse are undergoing substantial changes. Socio-linguistic work on narratives (Georgakopoulou 2007) has argued that earlier theories of life narratives subscribed to an implicit understanding of narratives as stable, autonomous and mono-perspectival entities, thus ignoring that in real, unfolding lives, narratives are often dialogical, multi-perspectival and fragmented. These insights have funneled into research on narrative in new media (Page \& Bronwen 2011), but they have yet to be put to work on narratives in political rhetoric. Connected to these matters is the question of the audience. The study of narratives in rhetorical discourse could benefit from researchers engaging with powerful tools of rhetorical narratology such as the notion of positioning (Phelan 2005b) for analyzing the ethical and value-generating interactions between textual form and readerly response.

\section{Bibliography}

\subsection{Works Cited}

Aristotle (1984). Rhetoric. J. Barnes (ed.). The Complete Works of Aristotle , Vol. Two. Princeton: Princeton UP.

Bamberg, Michael \& Molly Andrews (2004). Considering Counter-Narratives: Narrating, Resisting, Making Sense. Amsterdam: Benjamins.

Bitzer, Lloyd F. (1968). "The Rhetorical Situation." Philosophy and Rhetoric 1.1, 1-14.

Burke, Kenneth (1951). "Rhetoric Old and New." Journal of General Education 5, 202-09.

Fisher, Walther (1984). "Narration as a Human Communication Paradigm." 
$51,1-22$.

Fisher, Walther (1985). "The Narrative Paradigm: An Elaboration." Communication Monographs 52, 347-67.

Fisher, Walther (1987). Human Communication as Narration: Toward a Philosophy of Reason, Value and Action. Columbia: U of South Carolina P.

Georgakopoulou, Alexandra (2007). Small Stories, Interaction and Identities . Amsterdam: Benjamins.

Godall, H. L. (2010). Counter-Narrative: How Progressive Academics Can Challenge Extremists and Promote Social Justice. Walnut Creek, California: Left Coast $P$.

Hauser, Gerald A. (2002). Introduction to Rhetorical Theory. Long Grove, Illinois: Waveland Press Inc.

Holstein, James A. \& Jaber F. Gubrium, eds. (2012). Varieties of Narrative Analysis . London: Sage Publications.

Kirkwood, William G. (1992). "Narrative and the Rhetoric of Possibility."

Communication Monographs 59, 30-47.

Kjeldsen, Jens E. (2008). "Mediated publics and rhetorical fragmentation."

Democracy, Journalism and Technology: New Developments in an Enlarged Europe . Tartu: Tartu UP, 115-28.

Lucaites, John Louis \& Celeste Michelle Condit (1985). "Re-constructing Narrative Theory: A Functional Perspective." Journal of Communication 35.4, 90-108. MacIntyre, Alasdair (1981). After Virtue: A Study in Moral Theory. Notre Dame, Ind.: University of Notre Dame Press.

McClure, Kevin (2009). "Resurrecting the Narrative Paradigm: Identification and the Case of Young Earth Creationism." Rhetoric Society Quarterly 39.2, 189-211. Olbrechts-Tyteca, Lucie \& Chaïm Perelman (1958). Traité de l'argumentation: La nouvelle rhétorique. Paris: PUF.

Page, Ruth \& Thomas Bronwen, eds. (2011). New Narratives. Stories and Storytelling in the Digital Age. Lincoln: U of Nebraska P.

Phelan, James (2005a). "Rhetorical Narratology." D. Herman et al. (eds.). Routledge Encyclopedia of Narrative Theory. London: Routledge, 500-04. Phelan, James (2005b). Living to Tell about It: A Rhetoric and Ethics of Character Narration 
. Ithaca, NY: Cornell UP.

Polletta, Francesca (2006). It Was Like a Fever. Storytelling in Protest and Politics . Chicago: U of Chicago P.

Quintilian (1920). Institutio Oratoria. Quoted from:

http://penelope.uchicago.edu/Thayer/E/Roman/Texts/Quintilian/Institutio_Oratoria/4B*.htm [7]

Rowland, Robert (1989). "On Limiting the Narrative Paradigm: Three Case Studies." Communication Monographs 56, 39-54.

Rowland, Robert (2009). "The Narrative Perspective." J. Kuypers (ed.). Rhetorical Criticism. Perspectives in Action. Plymouth, MA: Lexington Books, 117-42.

Salmon, Christian ([2007] 2010). Storytelling: Bewitching the Modern Mind. London: Verso.

Stroud, Scott R. (2002). “Multivalent Narratives: Extending the Narrative Paradigm with Insights from Ancient Indian Philosophical Texts." Western Journal of Communication 66, 369-93.

Stroud, Scott R. (2003). “Narrative Translation Across Cultures: From the Bhagavad Gita to The Legend of Bagger Vance." Journal of Communication and Religion 26.1, 51-82.

Stroud, Scott R. (2004). "Narrative as Argument in the Indian Philosophy: The Astāvakra Gitā as Multivalent Narrative." Philosophy and Rhetoric 37, 42-71. Vatz, Richard E. (1973). "The Myth of the Rhetorical Situation." Philosophy and Rhetoric 6.3, 154-61.

Vatz, Richard E. (2009). "The Mythical Status of Situational Rhetoric: Implications for Rhetorical Critics' Relevance in the Public Arena." Review of Communication 9.1, $1-5$.

Walsh, Richard (2007). The Rhetoric of Fictionality. Columbus: Ohio State UP.

\subsection{Further Reading}

Charland, Maurice (1987). “Constitutive Rhetoric: The Case of the Peuple Québécois ." Quarterly Journal of Speech 73, 133-50.

Foss, Sonja K. (2004). "Narrative Rhetoric." Rhetorical Criticism: Exploration and Practice. Long Grove, Illinois: Waweland P., 333, 382. 
Hauser, Gerard (1999). Vernacular Voices: The Rhetoric of Publics and Public Spheres. Columbia: U of South Carolina P.

Lewis, William F. (1987). “Telling America's Story: Narrative Form and the Reagan Presidency." Quarterly Journal of Speech 73, 280-302.

To cite this entry, we recommend the following bibliographic format:

Iversen, Stefan: "Narratives in Rhetorical Discourse". In: Hühn, Peter et al. (eds.): the living handbook of narratology. Hamburg: Hamburg University. URL = http://www.Ihn.uni-hamburg.de/article/narratives-rhetorical-discourse [view date:12 Feb 2019] 